\title{
EXPANDING ACCESS TO HIV COUNSELLING AND TESTING AT SCHOOLS - THE MANGUZI EXPERIENCE
}

\author{
Colin Pfaff, MB BCh, MMed (Fam), DCh, Dip HIV Man, DA \\ Centre for Rural Health, University of the Witwatersrand
}

Johriaan de Beer, $B L C, M B A$

Programme Manager, Tholulwazi Uzivikele

South Africa's HIV epidemic disproportionately affects the youth. ${ }^{1}$ The importance of knowing one's status via voluntary counselling and testing (VCT) is recognised as a key strategy in fighting the epidemic and is reflected in the National Strategic Plan (NSP), ${ }^{2}$ which has set targets of $70 \%$ of all adults knowing their status by 2011 and $25 \%$ of all adults having been tested in the past 12 months. The Human Sciences Research Council survey in $2008^{1}$ showed that $50.8 \%$ of all South Africans 15 years and older have had an HIV test, pointing to wider acceptance of VCT. As a further response to reaching the NSP target, the national HIV counselling and testing campaign ${ }^{3}$ was launched in April 2010 with a focus on mobilising all South Africans to be tested for HIV and ensuring that every South African knows their HIV status. Both the NSP and the national HIV testing campaign recognise the importance of community mobilisation and community-based models of VCT to achieve these targets. The NSP in particular has a goal to expand successful strategies of testing outside health care facilities to cover $70 \%$ of all districts by 2011.

Young people are reluctant to use health care facilities, and several 'youth friendly' strategies have been tried to target adolescents. This case study serves to document the successes of one such community-based VCT strategy, aimed at young people in northern KwaZulu-Natal, South Africa.

\section{STUDY SETTING}

Tholulwazi Uzivikele (TU) ${ }^{4}$ is a non-profit organisation serving the communities surrounding Manguzi Hospital in northern KwaZulu-Natal. The area borders Mozambique and is extremely rural with poor access on sandy roads. Unemployment is estimated at $70 \%{ }^{5}$ and the antenatal HIV prevalence is $28 \%$. TU was founded in 2002 by concerned staff members at Manguzi Hospital wanting to mitigate the effect of the HIV epidemic on the surrounding community. The organisation started with an emphasis on orphans and vulnerable children and home-based care, but has subsequently expanded to include programmes for poverty relief, HIV prevention, and access to medical care and social services. Antiretroviral treatment (ART) is available at Manguzi Hospital and all 10 local clinics. CD4 tests can be done and ART initiated at any of these sites. Patients can usually commence treatment within 2 weeks of a diagnosis, and most of the population lives within a $10 \mathrm{~km}$ radius of such a clinic.

\section{DESCRIPTION OF ACTIVITIES}

The VCT programme was started by TU in August 2007. The aim of the programme was to increase HIV awareness and offer VCT in schools, using drama to sensitise, educate and encourage participation among the learners. This programme was made possible by close co-operation with the Department of Education and local school principals and teachers and financial and technical support from Oxfam OHAP. TU has built credibility over the years with these role-players, initially through the orphan programme. Principals realise the difficulties that learners face in accessing VCT and recognise that the programme meets an unmet learner need to access a non-judgemental, youth-friendly information service. Before this programme started, learners wanting to access VCT could only do so by going to the clinic, which often required the whole day away from school as most government VCT activities were not available on weekends.

In order to increase levels of participation by learners during the education process, it was decided to use 'forum drama'. While drama has been used for many years in the HIVIAIDS field, forum drama specifically encourages the audience to intervene and make decisions for the actors at various stages of the drama. The audience thus determines the eventual outcome of the story by the choices they have made, simulating real life. An organisation skilled in using forum drama for HIV awareness, Dramatic Change, ${ }^{6}$ provided training for all the actors. At the same time, all the actors were also trained as VCT counsellors by the Foundation for Professional Development, supported by funding from USAID. 
Of the 64 high schools in the Manguzi sub-district, 19 were initially targeted, being secondary level schools. The team visited each school on a 5-day programme. Most programme activities, such as sensitisation and drama, occurred during school hours. These activities were integrated into the school syllabus in subjects such as Life Orientation and sport with the participation of teachers.

The team consisted of four actors, who also functioned as educators and had all been trained as VCT counsellors. Several of the actors were HIV positive. During the first two days, the actors were invited as guest teachers and taught classes during the Life Orientation lessons at the schools. Topics covered included life skills, goal setting, vision and romantic relationships, moving on to the origin of HIVIAIDS, HIV as an infectious disease, stigma, transmission, prevention and VCT. On the third day the forum drama was performed for the entire school. The story line consisted of friends discussing relationships, social situations touching on peer pressure, abuse, and choices made with an emphasis on knowing one's status and avoiding risky situations. It was interrupted at regular intervals by a narrator who gave the audience the chance to make decisions for the actors or even to come on stage and play their role. The sessions were very interactive, as learners were given the opportunity to dramatise events from their own experience.

On the fourth day confidential counselling was offered to all students who might decide to test for HIV. The counselling and testing was conducted in temporary tent structures that allowed for discretion in terms of location. Learners could access testing at any time during the school day. The actors conducted the counselling and testing, with support from a nurse. The service was promoted as a health and life skills counselling service - not all learners who accessed the service were necessarily tested. The emphasis was placed on gaining more information and was rooted in psychosocial support and risk management strategies flowing from the drama of the previous day. Learners were provided with information, and only given the option of testing once they were comfortable. Learners who were diagnosed and confirmed as being HIV positive were referred to a local clinic, where CD4 testing and ART were available. The VCT team also provided ongoing psychosocial support for diagnosed individuals by phoning them within a week of the test being conducted and linking individuals in need of support to a local support group.

On the fifth day a talent search was conducted as a closure event, strengthening the relations with the programme and encouraging ongoing dialogue between learners. Often learners presented different drama plays around HIV awareness, from which the VCT team in turn learnt more about the context.

Through interaction with concerned school principals and teachers the VCT team also facilitated the establishment of 'HIV Champions' at schools. HIV Champions were teachers or student leaders who augmented the knowledge of students and teachers in a specific school and were selected on the basis of their willingness to lead and their interest in the future of youth. Support groups were also organised in the schools and structured as social clubs or sports clubs, without discriminating on the basis of HIV status.

\section{OUTCOMES}

During 2008 and 2009 all 19 secondary schools were visited once and 13 were visited twice; 12996 beneficiaries were reached with the awareness drama, and 2394 students were tested. HIV prevalence in the tested population was $2.8 \%$

In October 2009 the last three secondary schools on the schedule were visited again in order to evaluate the programme. The counsellors went to each school, surveying clients who had been tested previously. In each of the three schools, questionnaires were handed out to the first 79 clients who were found of the total of 217 who had been tested. All 79 forms were returned. Of the respondents, $91 \%$ felt that the counsellor was sympathetic throughout the counselling session, $94 \%$ felt that the service was done with confidentiality and privacy, and $100 \%$ said they would recommend the service to someone else. When asked how the service could be improved, most made comments such as 'well done' and 'keep it up'. Nine respondents gave minor suggestions as to how the service could be improved, e.g. by handing out T-shirts or refreshments after testing, and one respondent suggested that testing be done in a building rather than in a tent.

Evaluation of how many accessed ART or underwent any behaviour change will need to be more detailed and has not yet been done.

\section{DISCUSSION}

VCT services have been identified as an essential component of comprehensive HIV care. VCT is both an entry point to antiretroviral care and may promote behaviour change, particularly for those who test positive. ${ }^{7}$ However, VCT services are often underutilised. In South Africa, although rates of testing in adults aged 15 years and above increased from $21.4 \%$ in 2002 to $30.5 \%$ in $2005^{8}$ and $50.8 \%$ in $2008,{ }^{1}$ still almost half of South Africans have never had an HIV test. The 2005 study $^{8}$ showed that those in informal rural areas were less likely to know their status than those living in formal urban areas (19.3\% v. $40.4 \%)$.

There are several reasons for low uptake of VCT services, including confidentiality, concern about reaction from male partners, lack of access to free testing, transport costs, ${ }^{9}$ trust, stigma of being seen at a health care facility, ${ }^{10}$ and lack of perceived personal risk. ${ }^{11}$

Community-based strategies of VCT have been proposed as one way to address these barriers. Community-based strategies move the services closer to the people, but may also overcome stigma and confidentiality issues that are concerns in visiting a health care facility. Communitybased VCT has been shown to increase acceptability and rates of testing in several studies. Moving VCT to 
the workplace in Zimbabwe was associated with a $51.1 \%$ uptake of testing compared with offering vouchers for testing in the community, which resulted in a $19.2 \%$ uptake. ${ }^{12}$ Similarly, in Zimbabwe community-based VCT provided in a mobile van increased VCT uptake by $98 \%$ for 1000 rural women. ${ }^{13}$ In a feasibility study in Uganda many clients were found to prefer a mobile van to facilitybased testing. ${ }^{14}$

Another community-based strategy has been to offer VCT in the home. After collecting blood as part of a doorto-door health census, delivery of results to the home as opposed to collecting them at a facility increased the number of adults aged $25-54$ who accessed their results from $10 \%$ to $46 \%{ }^{15}$ Travel distance, facility waiting time and issues of confidentiality, including emotional composure during the walk home, were all cited by participants as factors favouring home-based VCT. Youth, however, were reluctant to receive results in the home, stating that the visit would invite questions and speculation by other family members. A recent Cochrane review of home-based VCT found that homebased testing or delivering results to the home rather than collecting them at the clinic leads to a higher uptake in testing, but cautioned that the literature was too limited to recommend large-scale implementation. ${ }^{16}$

Young people in particular are reluctant to use health services, and several strategies to target adolescents have been tried. The Department of Health has piloted a programme of 'youth friendly' clinics under the National Adolescent Friendly Clinic Initiative to try to address this situation. Several community-based VCT strategies have also been specifically aimed at making VCT more accessible to young people and increasing uptake. A review of these initiatives has highlighted their diversity and emphasised that there is no one ideal model for VCT in young people and that programmes must be innovative and tailored to meet the specific context and reach a specific target of young people. The review did note several key principles that these diverse youth-centred VCT programmes had in common. ${ }^{17}$ These included involving learners in the planning and delivery process, mobilising community-based peer educators, ensuring suitable accommodation to enable privacy, training providers in youth-friendly approaches, integrating posttesting services, and supplying educational material and condoms. Many of these principles feature in the TU VCT programme.

Drama has been recognised as a key medium to reach young people and has been used successfully to motivate adolescents to undertake HIV testing, both in South Africa ${ }^{18}$ and in Malawi. ${ }^{19}$ In Khayelitsha HIV testing increased by $172 \%$ in sites that had received a drama presentation compared with sites that had not. ${ }^{18}$

However, none of these drama programmes were combined with offering HIV testing as part of the same programme. Similarly, very little has been written about the process of taking VCT into the schools. In Uganda the Kitovu mission hospital has successfully provided a mobile VCT service in school settings whereby, at one outpost, a van is parked at the school and offers same-day testing. ${ }^{17}$ Mpilonhle, a non-governmental organisation working $200 \mathrm{~km}$ further south in the same district as TU, ${ }^{20}$ has developed a similar strategy, offering HIV testing as part of a general health check using mobile caravans on site at schools. This is combined with offering computer training at the same venue.

The HIV prevalence in students who were tested in Manguzi was $2.8 \%$. This is similar to the experience of Mpilonhle, where an HIV prevalence of $2.7 \%$ was found among high-school students who underwent voluntary testing (personal communication). Both programmes indicate that offering VCT in schools is both feasible and acceptable as part of a package of increasing provision of HIV care to young people.

\section{CONCLUSION}

South Africa has an ambitious NSP, but more needs to be done if the targets are to be met with the time remaining. The TU VCT programme is an example of a successful community-based VCT strategy that has been effective in reaching young people.

\section{REFERENCES}

1. Shisana O, Rehle T, Simbayi LC, et al. South African National HIV Prevalence, Incidence, Behaviour and Communication Survey 2008. A Turning Tide among Teenagers? Cape Town: HSRC Press, 2008.

2. Department of Health. HIV and AIDS and STI National Strategic Plan for South Africa 2007-2011. 2007. http://www.doh.gov.za/docs/misc/stratplan/2007-2011/ part2.PDF (accessed 6 February 2011).

3. SANAC secretariat. National HIV Counselling and Testing Campaign Strategy. 2010 http://www.capegateway.gov.za/other/2010/6/hct_campaign_strategy_2_3_10_final. pdf (accessed 6 February 2011).

4. Tholulwazi Uzivikele. Empower yourself through knowledge. http://www.tuproject. org (accessed 11 April 2010).

5. Umhlabuyalingana Municipality IDP Review 2007/2008. http://devplan.kzntl.gov.za/ idp reviewed 2007 8/IDPS/KZ271/../11.pdf, URL (accessed 23 November 2009).

6. Dramatic change: Zisize drama project. //www.adcid.org/zisize.html (accessed 11 April 2010)

7. Solomon V, Van Rooyen H, Griesel R, Gray D, Stein J, Nott V. Critical Review and Analysis of Voluntary Counselling and Testing - Literature in Africa. Durban: Health Systems Trust, 2004

8. Shisana O, Rehle T, Simbayi LC, et al. South African National HIV Prevalence, HIV Incidence, Behaviour and Communication Survey 2005. Cape Town: HSRC Press, 2005.

9. Urassa P, Gosling R, Pool R, Reyburn H. Attitudes to voluntary counselling and testing prior to the offer of nevirapine to prevent vertical transmission of HIV in northern Tanzania. AIDS Care 2005;17:842-852.

10. Kalichman SC, Simbayi LC. HIV testing attitudes, AIDS stigma, and voluntary HIV counselling and testing in a black township in Cape Town, South Africa. Sex Transm Infect 2003;79:442-447.

11. Nakanjako D, Kamya M, Kyabayinze D, et al. Acceptance of routine testing for HIV among adult patients at the medical emergency unit at a national referral hospital in Kampala, Uganda. AIDS Behav 2006;11:753-758.

12. Corbett EL, Dauya E, Matambo R, et al. Uptake of workplace HIV counselling and testing: a cluster-randomised trial in Zimbabwe. PLoS Med 2006;3:e238.

13. Morin SF, Khumalo-Sakutukwa G, Charlebois ED, et al. Removing barriers to knowing HIV status: same-day mobile testing in Zimbabwe. J Acquir Immune Defic Syndr 2006;24:218-224.

14. Asingwire N. Feasibility study of the mobile van for voluntary counselling and testing for HIV / AIDS. Final report submitted to the Uganda Program for Human and Holistic Development (UPHOLD), Kampala, Uganda. 2004. http://www.uphold.jsi.com/Docs/ Mobile_Van_VCT.pdf (accessed 31 December 2009).

15. Wolff B, Nyanzi B, Katongole G, Ssensanga D, Ruberantwari A, Whitworth J. Evaluation of home based voluntary counselling and testing intervention in rural Uganda. Health Policy Plan 2005;20(2):109-116.

16. Bateganya MH, Abdulwadud OA, Kiene SM. Home based HIV voluntary counseling and testing in developing countries. Cochrane Database Syst Rev 2007;4.

17. Boswell D, Baggely R. Voluntary Counseling and Testing Young People: A Summary Overview. Arlington, VA: Family Health International, 2002: 6.

18. Middelkoop K, Myer L, Smit J, Wood R, Bekker LG. Design and evaluation of a drama-based intervention to promote voluntary counseling and HIV testing in a South African community. Sex Transm Dis 2006;33:524-526.

19. Rumsey DS, Brabin L, Mfutso-Bengo J-M, Cuevas LE, Hogg A, Brabin BJ. Effectiveness of drama in promoting voluntary HIV counseling and testing in rural villages in southern Malawi. Int J STD AIDS 2004;15:494-495.

20. Mpilonhle - Programmes: Health screening. http://www.mplionhle.org/programmes health_screening.php (accessed 11 April 2010). 